\title{
Laser-Based Joining of Thermoplastics to Metals: Influence of Varied Ambient Conditions on Joint Performance and Microstructure
}

\author{
Klaus Schricker, Martin Stambke, Jean Pierre Bergmann, and Kevin Bräutigam \\ Department of Production Technology, Ilmenau University of Technology, Gustav-Kirchhoff-Platz 2, 98693 Ilmenau, Germany \\ Correspondence should be addressed to Klaus Schricker; klaus.schricker@tu-ilmenau.de
}

Received 2 June 2016; Revised 26 August 2016; Accepted 19 October 2016

Academic Editor: De-Yi Wang

Copyright (C) 2016 Klaus Schricker et al. This is an open access article distributed under the Creative Commons Attribution License, which permits unrestricted use, distribution, and reproduction in any medium, provided the original work is properly cited.

\begin{abstract}
Laser-based joining of thermoplastics to metals shows a great potential for functional design especially in terms of lightweight constructions. In the joining process, the joining speed and the energy per unit length, respectively, show an influence on timetemperature profiles measured in the joining zone. The time-temperature profile affects the joining zone and consequently the joint behavior in mechanical testing. In the current investigation, the joining zone was characterized by the melting layer. Moreover, the mechanical properties of the joint by tensile shear testing and the fracture mode were investigated. Based on the results obtained, three sets of joining speeds/energies per unit length with different mechanical behaviors were selected for further investigations under varied ambient conditions. Thereby, the influence of outdoor weathering as well as aging above the glass transition temperature of the plastic part on the joint's performance was compared with the nonaged joints.
\end{abstract}

\section{Introduction}

Composite constructions are gaining importance in automotive industries and mechanical engineering due to legal requirements, for example, environmental aspects associated with reduced emission values, and more efficient constructions, for example, the weight reduction of moving parts in machine-tools. Particularly the use of materials with different characteristics shows the possibility for novel constructions with a high functional density and provides a new engineering approach to enhance loadability, stiffness, or fatigue of components without an increase in weight. The implementation of this approach depends on the key factor of joining technology to realize multimaterial-designs by using newly deployed materials.

Metal-thermoplastic joints show a high potential concerning the above-mentioned points. However, metals and thermoplastics have fundamentally different physical characteristics, preventing the use of common processes like fusion welding. Furthermore, mechanical joining methods possess disadvantages due to stress peaks and notches, for example, in screwed joints, and adhesive bonding regarding long hardening times. In contrast, thermal joining allows direct connection between both materials, enabling a flat and firmly bonded joint with high loadability. In thermal joining, a sufficient heat flux can melt the thermoplastic material at the boundary layer between both joining partners. The molten material penetrates the structures of the metal and wets its surface. After solidification of the thermoplastic, a permanent joint is formed. The process can be performed by a conductor [1], an inductor [2], friction joining [3], ultrasonic [4] and resistance welding [5], or laser radiation [6]. The use of the laser shows advantages over competitive processes, because of a geometrically independent and locally limited joint zone. In addition, the adjustment of a specific time-temperature profile depending on the properties of the selected materials is possible. The process can be performed as transmission or heat conduction joining. In transmission joining, the laser beam is passed through the thermoplastic joining partner and is partially absorbed at the metal surface towards the boundary layer. The thermoplastic material gets molten by thermal conduction at the contact area and is able to form a joint as described. In heat conduction joining, the laser is targeted at the metal surface as upper joining partner and 
the resulting heat is conducted through the metal plate into the joining zone. In contrast to transmission joining, the transmissivity of the thermoplastic within laser wavelength is not necessary and a high thermal load of the thermoplastic due to the absorption of the laser beam at the contact area can be prevented.

Various investigations were conducted to understand different features of laser joining. In the field of process strategy, Jung et al. [7] and Katayama et al. [8] showed the influence of transmission and heat conduction joining. In terms of bonding mechanisms, Kawahito and Katayama [9] and Arai et al. [10] detected firm bonding between metal and plastic. Markovits et al. [11] demonstrated the influence of locking mechanism to achieve a higher loadability of the joint. To achieve a suitable interlocking, surface preparation of the metal sheet is required. Various surface preparation methods were investigated such as laser-based processes $[12,13]$, chemical etching [14], corundum blasting [15], and machining [16]. Independent of the structuring process, structure density and a sufficient number of undercuts showed the highest influence on the joint's strength. On the basis of surface preparation, three different fracture modes can be distinguished by process management according to Wahba et al. [17]: the interface fracture at the boundary layer, a mixed fracture within the boundary layer and base material, and a base plastic fracture. Further investigations on mechanical behavior exist for monotonic [12] as well as for cyclic loads ([4] on ultrasonic welding). A correlation between thermoplastic morphology and mechanical behavior does not exist yet, as it was shown for laser transmission welding of plastics in Ghorbel et al. [18] and Al-Wohoush and Kamal [19], although a morphological characterization for spot joints was published in Schricker et al. [20].

Besides mechanical loads, the impact of varied ambient conditions on loadability is shown in Amend et al. [21] and Roesner [22] for climate and corrosion tests depending on varied surface structures, respectively, structure density. This paper gives a comprehensive relation between morphological parameters, time-temperature profiles, and mechanical properties due to aging effects.

\section{Experimental Setup}

The experimental investigations were performed using a fiber-coupled diode laser (Laserline LDM 3000, $\lambda=980 \mathrm{~nm}$, and $P_{L, \max }=3 \mathrm{~kW}$ ) with a spot diameter of $6 \mathrm{~mm}$, a laser beam power $\left(P_{L}\right)$ of $1 \mathrm{~kW}$, a dwell time $\left(t_{d}\right)$ of $8 \mathrm{~s}$ at seam start, and a joining pressure of $0.5 \mathrm{~N} \cdot \mathrm{mm}^{-2}$ within joint zone. The experimental setup is shown in Figure 1(a). As materials, an aluminum alloy (EN AW 6082 according to DIN EN 573-3 [23]) with $t=1.5 \mathrm{~mm}$ and Polyamide 6.6 (Nylon 6.6, PA 6.6) with $t=2 \mathrm{~mm}$ were used. The process was carried out as heat conduction joining. The metal surface was prepared by a $20 \mathrm{~W}$ fiber-laser (Rofin PowerLine F20) with lineshaped structures in joining direction (width: $25 \mu \mathrm{m}$, depth: $30 \mu \mathrm{m}$, and structure density: 28 lines $\mathrm{mm}^{-1}$, Figure 1(b)) to enhance the joint loadability. The overlap configuration of the specimens is shown in Figure 2(a).

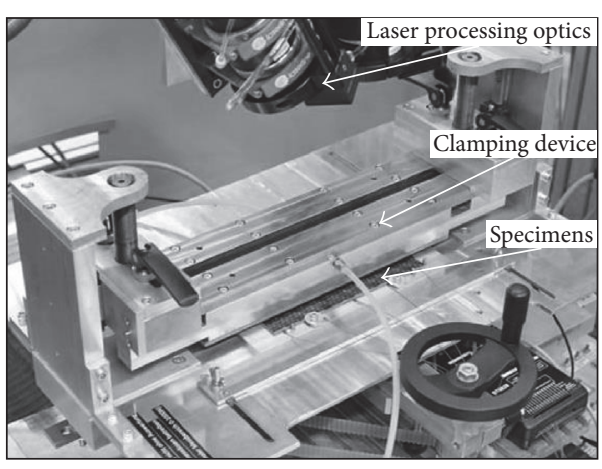

(a)

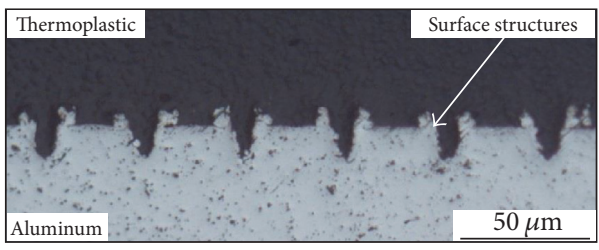

(b)

FIGURE 1: (a) Experimental setup and (b) surface morphology of the metal joining partner.

Based on this experimental setup, the joining speed was varied in order to adjust the time-temperature profile, thermoplastic morphology, and mechanical behavior. The time-temperature profile was recorded by a thermocouple type K (diameter: $0.2 \mathrm{~mm}$ ) within the joint zone (Figure 2(a)) with a recording rate of $100 \mathrm{~Hz}$ using a Dewetron DEWE 800 system. These results were linked to investigations of the thermoplastic melting layer. The microsections were cut out after a joint length of $75 \mathrm{~mm}$ (Figure 2(a)). Thereby, the weld zone is described by the melting layer thickness. Microsections for further investigations on the thermoplastic morphology were taken at the maximum of the melting layer and the edge of the lap joint (Figure 2(b)). The specimens were prepared by sputtering with ionized argon and examined by differential interference contrast microscopy (DIC). The mechanical behavior was characterized by tensile shear testing (test speed: $240 \mathrm{~mm} \cdot \mathrm{min}^{-1}$, sample width: $50 \mathrm{~mm}$, see Figure 2(a)) with a clamping length of $30 \mathrm{~mm}$. The sample width was selected based on industrial automotive testing standards. The high test speed was set to limit the influence of ductility in mechanical testing. Thereby, the influence of joining speed and time-temperature profile on mechanical properties can be shown.

Based on the results obtained, three sets of parameters were selected to identify the influence of different ambient conditions on the joint's mechanical performance. The aging behavior according to outdoor weathering was performed based on DIN EN ISO 877-1 for 12 weeks [24]. The test station was aligned to south at an angle of $45^{\circ}$. A meteorological station recorded atmospheric temperature, global radiation, rainfall, ozone, and humidity to correlate possible effects. Tensile shear test specimens were taken out of the test station, mechanically tested within 60 minutes, and compared to 


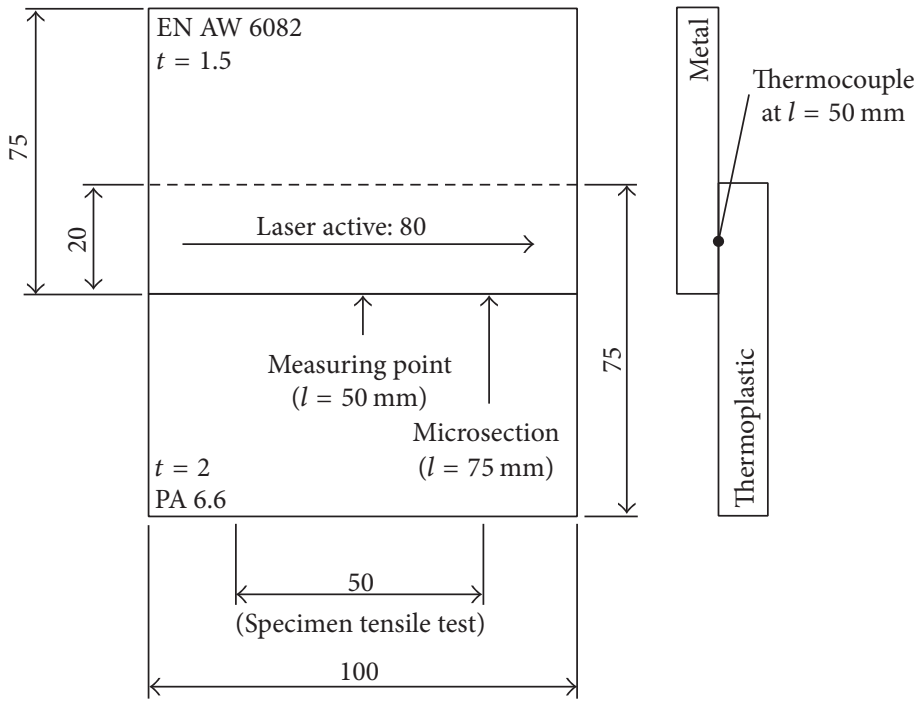

(a)

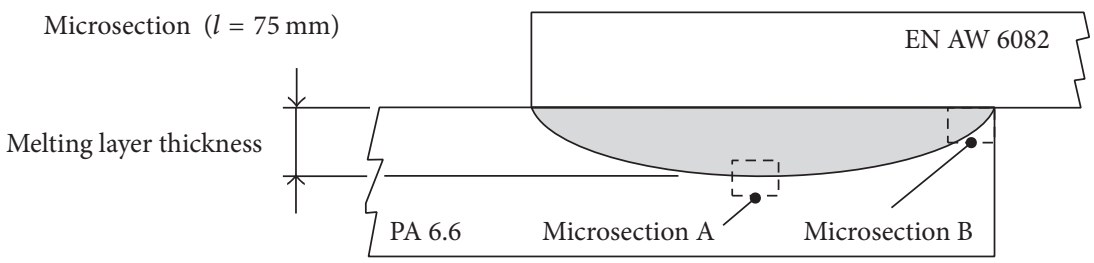

(b)

FIGURE 2: (a) Overlap configuration and sample-taking; (b) microsections.

stored reference specimens every seven days. Furthermore, the joint was thermally aged above glass transition temperature $\left(T_{g} \approx 85^{\circ} \mathrm{C}\right)$ at $155^{\circ} \mathrm{C} \pm 3 \mathrm{~K}$ to investigate the crystallization of amorphous areas within the polymer and the impact on mechanical properties. The test time was set to seven days. Specimens for tensile shear test were taken out every 24 hours.

Besides mechanical properties, the morphology and thermal behavior of the joints were examined. A differential scanning calorimetry (DSC, Netzsch DSC 204 F1) with the heating rate of $10 \mathrm{~K} \cdot \mathrm{min}^{-1}$ was used for material characterization in a temperature interval from $25^{\circ} \mathrm{C}$ up to $300^{\circ} \mathrm{C}$. The heat of crystallization in heating phase, $\Delta H$, was used for characterization of the crystallinity. The temperatures of initial melting range $T_{\mathrm{im}}\left(240^{\circ} \mathrm{C}\right)$ in heating phase and initial solidification range $T_{\text {ic }}\left(230^{\circ} \mathrm{C}\right)$ in cooling phase were examined, too. The specimens were taken out from the base material to identify the influence of aging on the material and joint behavior.

The results allow a correlation between time-temperature profile and morphology as well as the influence of aging effects on mechanical properties and fracture behavior for laser-manufactured metal-plastic joints.

\section{Results and Discussion}

3.1. Melting Layer and Mechanical Properties in Laser-Based Thermal Joining. In laser-based joining of metals to plastics, a characteristic time-temperature profile occurs depending on beam power, beam intensity and profile, materials, and joint geometry. In this work, the joining speed was varied from $2 \mathrm{~mm} \cdot \mathrm{s}^{-1}$ up to $7 \mathrm{~mm} \cdot \mathrm{s}^{-1}$ with $1 \mathrm{~mm} \cdot \mathrm{s}^{-1}$ intervals to obtain different time-temperature profiles. Within this speed interval, massive thermal degradation of the plastic is avoided at lower joining speeds. Molten polymer completely wet the whole overlap width and was ejected at the edges of the overlap (Figure 3(a)). The weld width in this parameter field is identical to the overlap width due to the high thermal conductivity of aluminum. Figure 3(b) shows the time-temperature profiles at different joining speeds for 80 seconds. The process starts at $0 \mathrm{~s}$ and the dwell time of $8 \mathrm{~s}$ is shown in the figure as $t_{d}$.

The maximum temperature and position depends on the joining speed. Due to the dwell time and the moving laser, the temperature increases and the maximum is reached when the spot passes the measuring point. Thereby, a maximum temperature between $305^{\circ} \mathrm{C}$ and $365^{\circ} \mathrm{C}$, depending on joining speed, was reached. Afterwards, the temperature decreases and an inflection point, corresponding to the end of the laser process, occurs. Based on material depending temperatures, temperature of initial melting range $T_{\mathrm{im}}\left(\mathrm{PA} 6.6: 240^{\circ} \mathrm{C}\right)$ and initial solidification range $T_{\mathrm{ic}}\left(\mathrm{PA} 6.6: 230^{\circ} \mathrm{C}\right)$, the thermoplastic material is molten during the process within the time interval $(\Delta t)$ between $T_{\text {im }}$ in heating phase and $T_{\mathrm{ic}}$ in cooling phase as described by Schricker et al. [25]. By increasing the joining speed, the time interval $\Delta t$ is getting smaller and less 


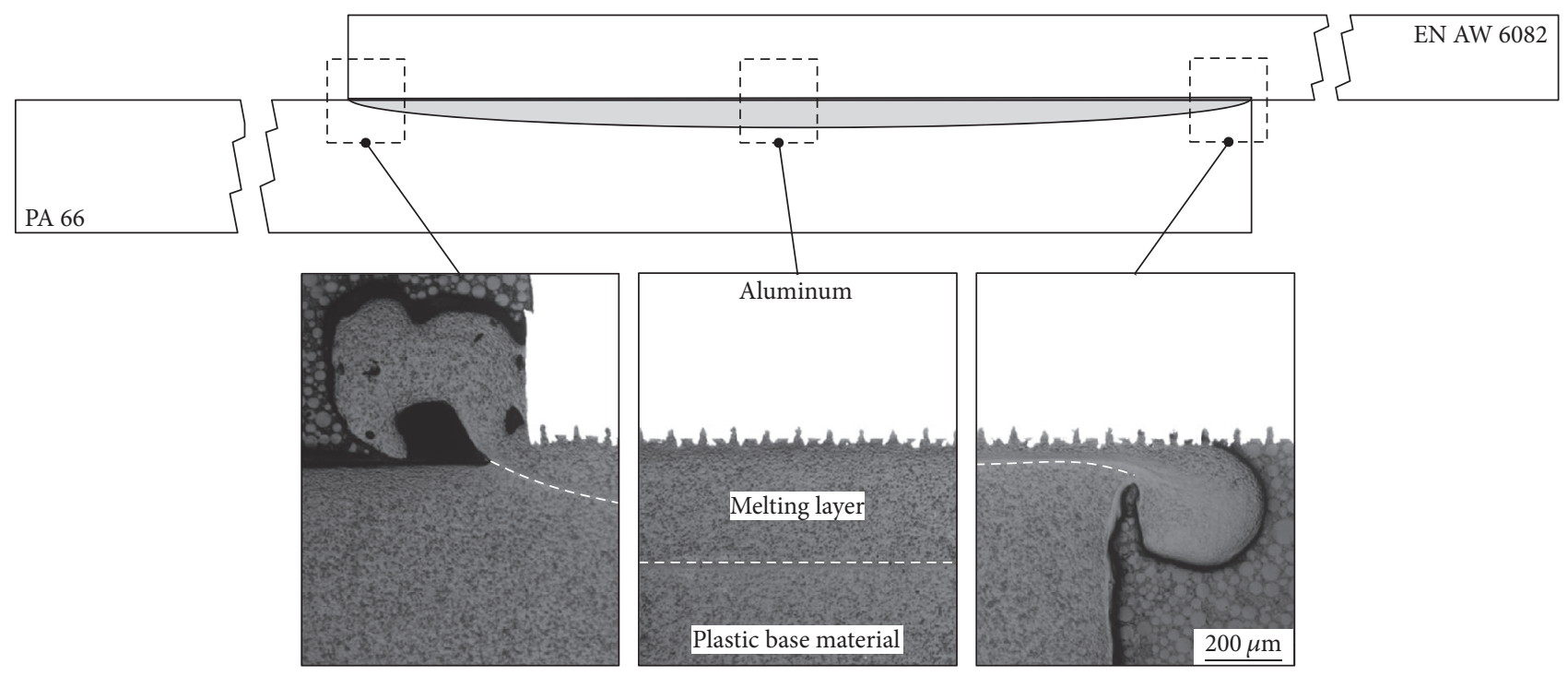

(a)

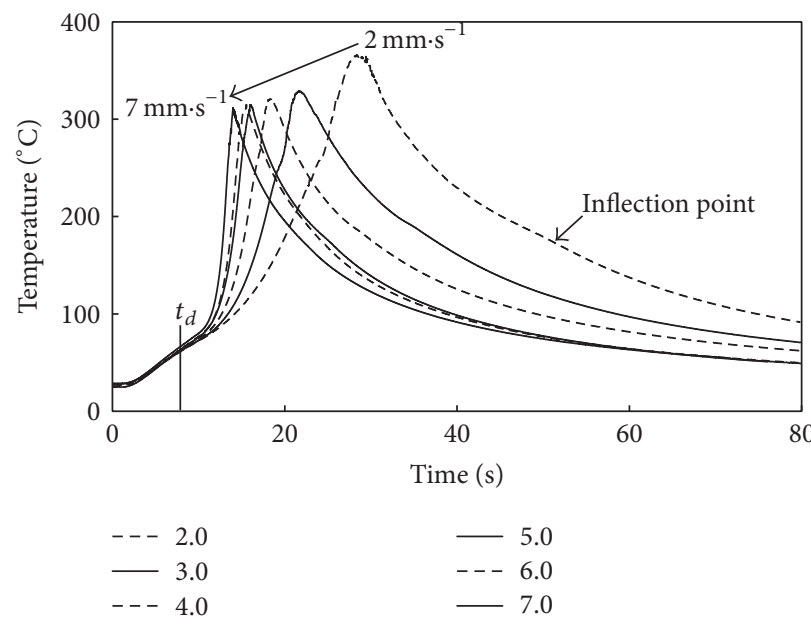

(b)

FIGURE 3: (a) Overlap width is equivalent to weld width (characteristic example for joining speed $4 \mathrm{~mm} \cdot \mathrm{s}^{-1}$ ). (b) Temperature-time profiles from $2 \mathrm{~mm} \cdot \mathrm{s}^{-1}$ up to $7 \mathrm{~mm} \cdot \mathrm{s}^{-1}$.

time is available for wetting (Figure 4). Moreover, the plastic base material is less thermally influenced due to a reduced energy input.

The influence of time-temperature profiles on the thermoplastic material can be characterized, for instance, by the changes in the thickness of the melting layer. In this paper, however, the time-temperature profiles are not correlated directly to the melting layer's thickness, because microsections and thermocouples were not in the same position. Such correlation can be found in Schricker et al. [25]. Instead, the melting layer thickness is correlated to the joining speed and the energy per unit length.

Figure 5 shows the correlation between the thickness of the melting layer and the joining speed. Starting from $560 \mu \mathrm{m}$ at $2 \mathrm{~mm} \cdot \mathrm{s}^{-1}$, the thickness was decreased to $286 \mu \mathrm{m}$ at $7 \mathrm{~mm} \cdot \mathrm{s}^{-1}$ due to the reduced energy input by increasing the joining speed as well as reduced time interval $\Delta t$. Moreover,
Figure 6 illustrates the correlation between the melting layer's thickness and the energy per unit length $\left(E=P_{L} \cdot v^{-1}\right)$. The correlation between melting layer's thickness and energy per unit length corresponds to process efficiency in laser material processing according to Hügel and Graf [26]. E reached values between $143 \mathrm{~kJ} \cdot \mathrm{m}^{-1}$ and $500 \mathrm{~kJ} \cdot \mathrm{m}^{-1}$ without melting the aluminum due to the large spot diameter of $6 \mathrm{~mm}$.

It should be noted that the melting layer thickness can be adjusted by altering the joining speed and energy per unit length. Therefore, the thermoplastic morphology within the melting layer changes, too.

Figure 7 shows microsections of the maximum and edge of the melting layer within PA6.6 (according to Figure 2(b)) for two different joining speeds. Within the thermoplastic morphology, four different zon es can be determined: the molten zone (1), a zone of fine microstructure (2), a partially molten zone (3), and the heat affected zone and 


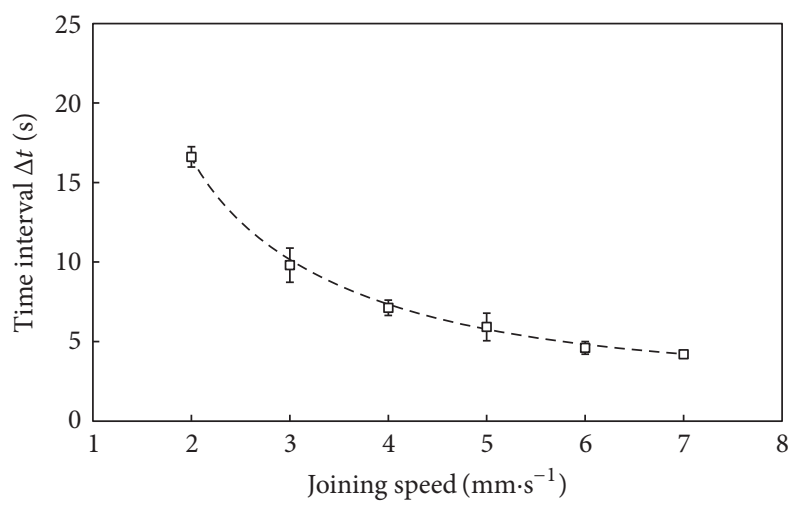

FIGURE 4: The influence of joining speed on the time interval of molten polymer at the boundary layer.

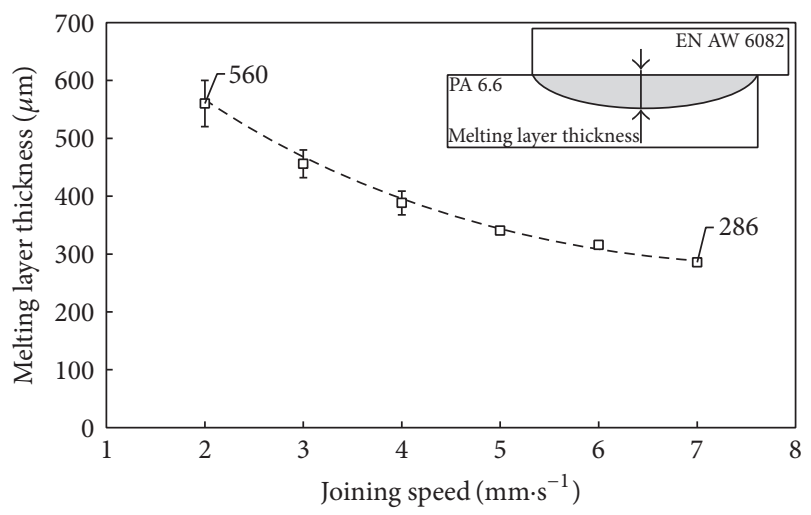

FIGURE 5: Melting layer thickness depending on joining speed.

base material (4). The time-temperature profile of the laser process influences these areas. On one hand, varied sizes of microstructures are caused by a high cooling rate due to nucleation, for example, between zone (1) and zone (2). On the other hand, the polymer is not completely molten in zone (3). For this reason, the described time interval $\Delta t$ is considered between $T_{\mathrm{im}}$ and $T_{\mathrm{ic}}$. These partially molten structures can be evidently deformed at the edge (position $B$ in Figures 7(a) and 7(b)) by the melt pool movement due to joining pressure and the related melt ejection. These areas can be determined independent of the joining speed and $\Delta t$ (Figures $7(a)$ and $7(b)$ ), even if the thickness of these areas is changing.

Besides a change in morphology (Figure 7) and melting layer's thickness (see Figures 5 and 6), the mechanical properties were also influenced by the process management. Figure 8 shows characteristic force-crosshead travel graphs for varied joining speeds during tensile shear testing. For the joining speed of $2 \mathrm{~mm} \cdot \mathrm{s}^{-1}$, a fracture within plastic base material near the joining zone was reached with a maximum force of approximately $4 \mathrm{kN}$ and a brittle fracture behavior. By increasing the joining speed, the maximum crosshead travel was increasing, too. The failure within plastic base material remained, even when higher force and crosshead travel were reached. However, by increasing the joining speed

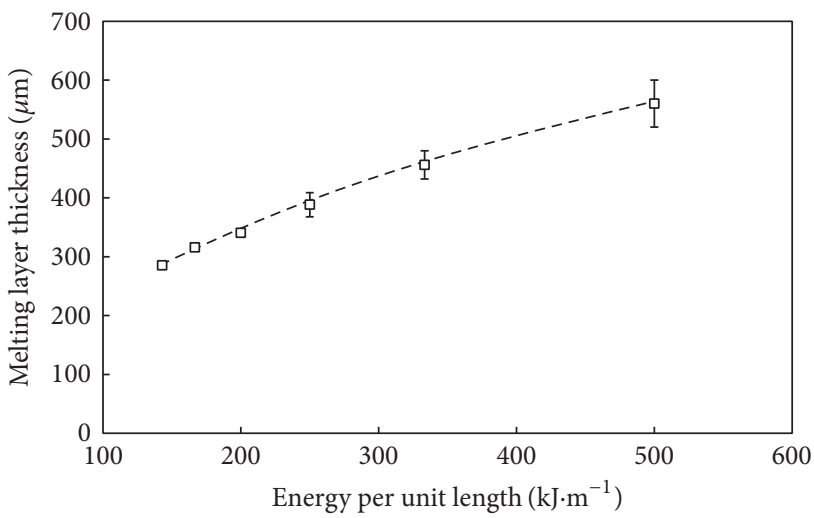

FIGURE 6: Melting layer thickness depending on energy per unit length.

the fracture mode changes to ductile, as shown for the joining speed of $6 \mathrm{~mm} \cdot \mathrm{s}^{-1}$ in Figure 8. It is believed that the necking within PA6.6 begins at the plateau when the maximum force was reached.

A potential explanation for this behavior is the higher percentage of existing amorphous areas by increasing the joining time, since the amorphous parts show a greater ductility compared to the crystalline areas. Increasing the joining speed results in a narrow time-temperature profile and a higher cooling rate (see Figure 3(b)), leading to an increase in the amorphous areas. Furthermore, the changes in the morphology of PA6.6 in the heat affected zone can affect the failure behavior, because failure occurred always in the heat affected zone in the polymer base material. The named parameters as well as the notch effect by the molten polymer ejection, the crack initiation, and crack growth depending on morphology are objects of future investigations. In all cases, the joint strength was greater than the plastic base material strength.

To further analyze the aging behavior of the joints, three joining speeds were selected from 2 to $4 \mathrm{~mm} \cdot \mathrm{s}^{-1}$. Compared to each other, these joining speeds show a significantly different mechanical behavior, even if the fracture was always within the plastic base material. Therefore, the influence of outdoor weathering and thermal aging on fracture mode, force-crosshead travel graphs, and the morphology of PA6.6 will be shown next.

3.2. Outdoor Weathering. The joints were aged under outdoor weathering conditions to determine the influence on mechanical properties of the joints. During outdoor weathering, the climate data were recorded. The average air temperature was between $6^{\circ} \mathrm{C}$ and $-1.2^{\circ} \mathrm{C}$ from October to February and the added up precipitation (rain/snow) per week was between 0 and 44.5 litre $\cdot \mathrm{m}^{-2}$.

Figure 9 shows the maximum force obtained after tensile shear testing depending on the weathering time in weeks. Reference specimens, which were not exposed to outdoor weathering and stored indoor, are shown for the beginning of the experiment ("0") and after 12 weeks ("Ref"). Both sets of specimens show a comparable average ultimate force 

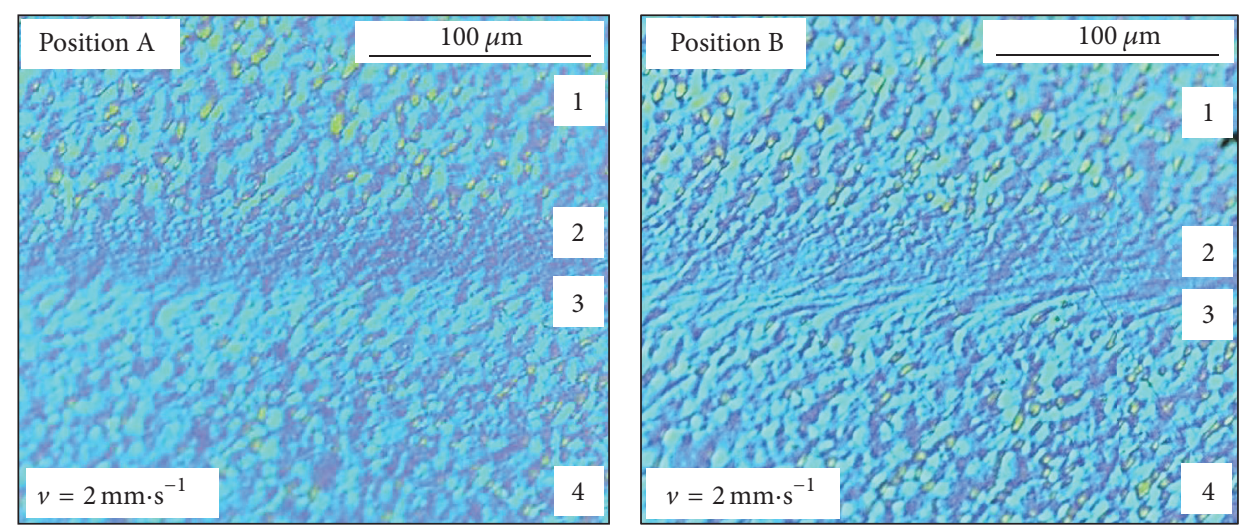

(a)
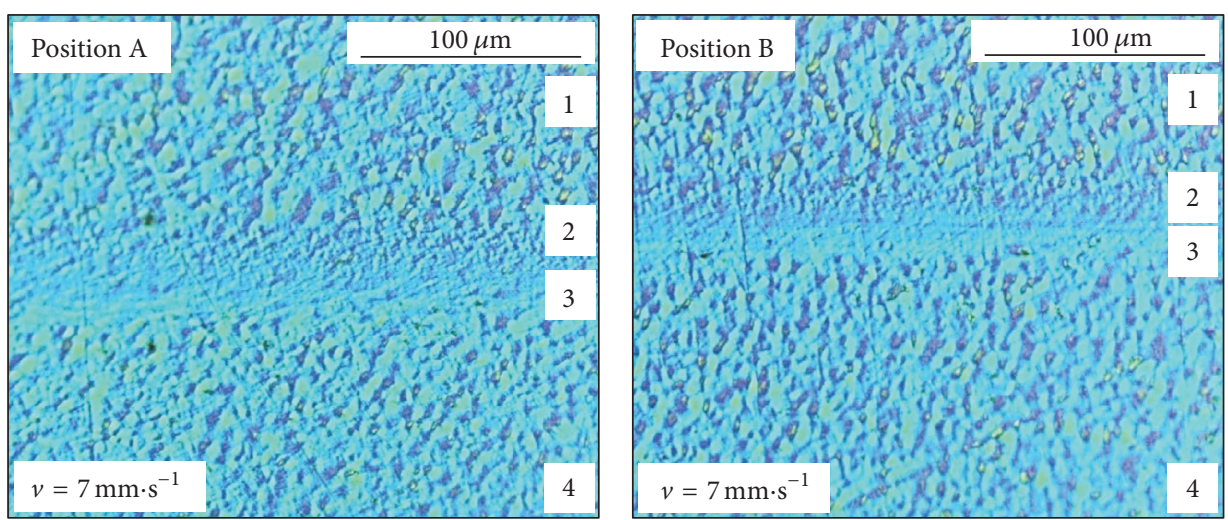

(b)

FIgURE 7: Morphology of the melting layer for (a) $2 \mathrm{~mm} \cdot \mathrm{s}^{-1}$ and (b) $7 \mathrm{~mm} \cdot \mathrm{s}^{-1}$ at maximum (A) and edge position (B).

depending on the joining speed, as already discussed in Section 3.1.

Because of the weathering conditions, the average forces obtained decreased significantly to approximately $3.5 \mathrm{kN}$ for all the joining speeds after 12 weeks of weathering (Figure 9). Furthermore, no difference in the joint's strength based on the selected joining speed was identified after 12 weeks of weathering. Nevertheless, the fracture occurred always within the PA6.6 base material, similar to the joints before weathering.

To explain the effects of the weathering conditions, a typical force-crosshead travel curve for each week is shown in Figure 10 (as an example for the joining speed of $4 \mathrm{~mm} \cdot \mathrm{s}^{-1}$ ). As can be seen, the crosshead travel increased to $130 \mathrm{~mm}$ in week $10(10 \mathrm{w})$. In contrast, the maximum force decreased to approximately $3.5 \mathrm{kN}$ after 10 weeks. As the weathering time increases week by week, the absorption of moisture increases as well, leading to the plasticization of PA6.6. Polyamide is known as a plastic with high moisture absorption [27]. The plasticization of PA6.6 increases the crosshead travel (plateau part of the curve) while reducing the joint's strength during tensile shear testing as can be seen in Figure 10. In additional, specimens were stored in water for 14 days (weight increase ca. $2.5 \%$ ) and showed a similar behavior (maximum force: ca. $4.5 \mathrm{kN}$, crosshead travel: ca. $70 \mathrm{~mm}$ ) to comprehend this effect. In weeks $11(11 \mathrm{w})$ and $12(12 \mathrm{w})$, a reduced crosshead travel was reached, although the ultimate force remained constant. A correlation to the climate data could explain this effect. Within these two weeks, the average air temperatures of $-1.2^{\circ} \mathrm{C}$ and $-0.3^{\circ} \mathrm{C}$ were the lowest during the examined time period which is a possible approach to explain this behavior.

A comparison between the joining speeds of $2 \mathrm{~mm} \cdot \mathrm{s}^{-1}$ and $4 \mathrm{~mm} \cdot \mathrm{s}^{-1}$ presents the harmonization in mechanical behavior after outdoor weathering (Figure 11). The reference specimens showed the same behavior as discussed in Section 3.1. After 12 weeks of weathering, the force-crosshead travel graphs of both joining speeds were harmonizing concerning their mechanical behavior. The necking started at a crosshead travel of about $1 \mathrm{~mm}$ and the force reached a plateau at approximately $3.7 \mathrm{kN}$ for both curves. Further investigations on the influence of weathering conditions on the physical properties of PA6.6 by DCS analysis did not confirm any changes. The melting temperature as well as the crystallization temperature was not affected by the selected period of outdoor weathering, although the characterization of the mentioned temperatures by DSC for Polyamide 6.6 is reported to be challenging [27]. 

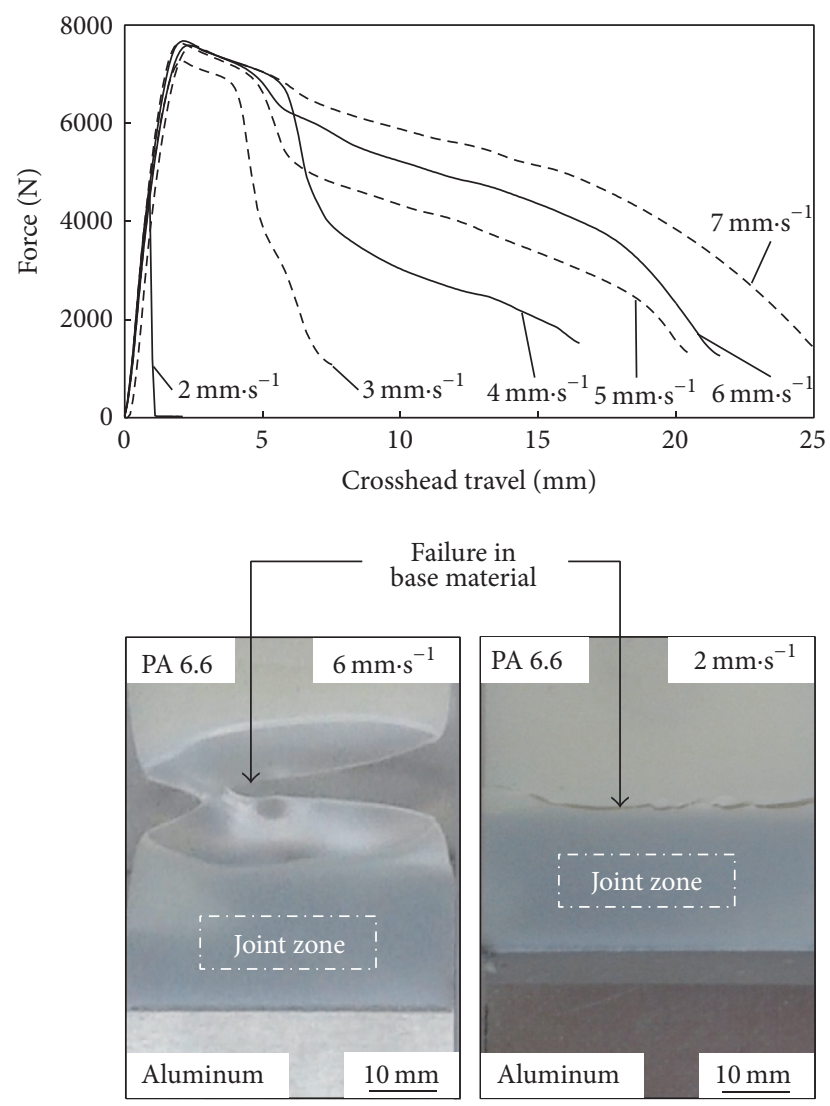

Top view on tensile shear samples after testing

FIGURE 8: Force-crosshead travel graphs for varied joining speeds.

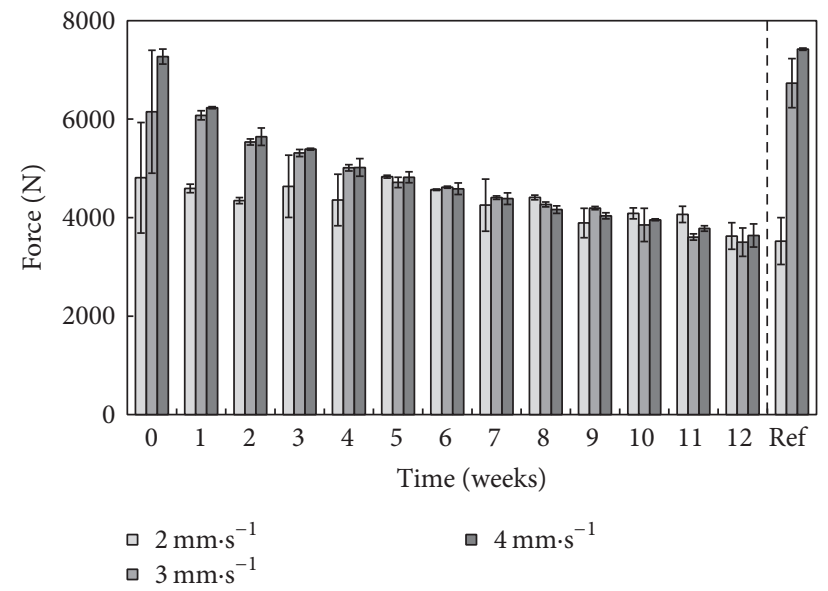

FIGURE 9: Influence of outdoor weathering on the joint's strength produced by various joining speeds.

3.3. Aging Above Glass Transition Temperature. Figure 12 shows the maximum reached forces in tensile shear testing after aging the joints above glass transition temperature of PA6.6 at $155^{\circ} \mathrm{C} \pm 3 \mathrm{~K}$ for up to seven days. The reference specimens (shown as "0") were tested prior to aging, which show the average forces from $4.8 \mathrm{kN}$ to $7.3 \mathrm{kN}$ depending on the joining speed. The initial situation is similar to the

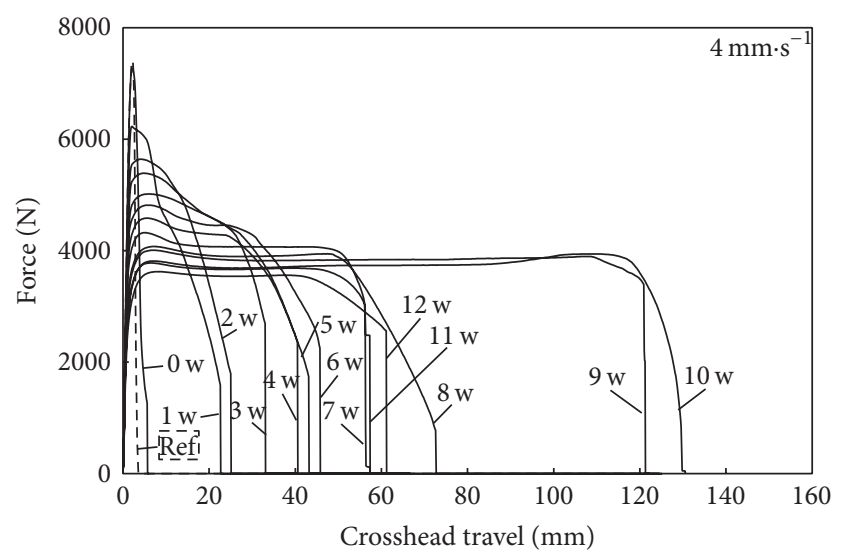

FIGURE 10: Typical force-crosshead travel graphs for each week (w) during outdoor weathering (joining speed: $4 \mathrm{~mm} \cdot \mathrm{s}^{-1}$ ).

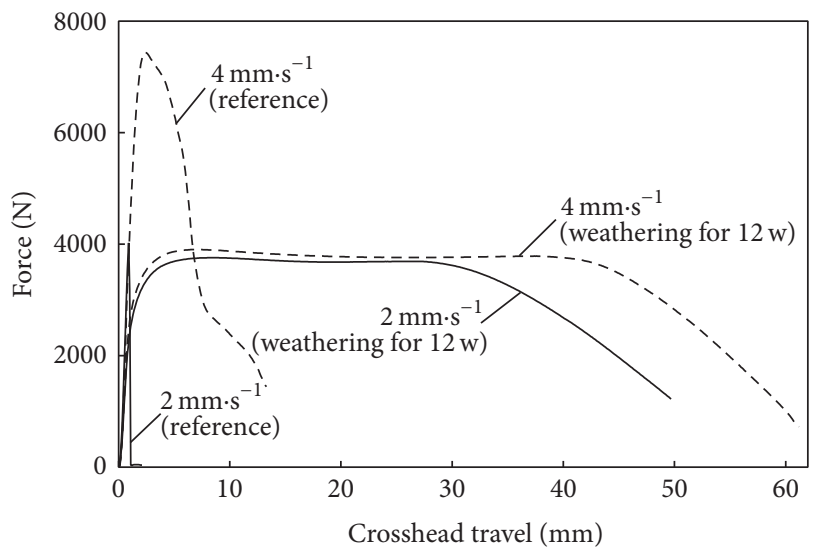

FIGURE 11: Comparison between reference specimens and specimens after 12 weeks of outdoor weathering for different joining speeds.

force-crosshead travel graphs shown in Figure 9 and the explanation in Section 3.1. After the aging, the maximum force decreased to a mean value of $2.7 \mathrm{kN}$ independent of the joining speed. Individual variances in the force for each joining speed are not considered in this discussion because they lie within the standard deviations.

Furthermore, Figure 12 shows the fracture mode for a joining speed of $4 \mathrm{~mm} \cdot \mathrm{s}^{-1}$. After one day at this temperature, a brittle fracture behavior occurs within the plastic base material. After seven days, the fracture mode is comparable to shorter aging times, but the intensity of yellowing is significantly increased. Figure 13 shows a representation of these results in correlation to the aging times, as an example for the joining speed of $4 \mathrm{~mm} \cdot \mathrm{s}^{-1}$. The reference specimens showed a mean force of $7.3 \mathrm{kN}$ and a mean crosshead travel of $6 \mathrm{~mm}$. The mean force and crosshead travel were significantly decreased to $2.6 \mathrm{kN}$ and $0.8 \mathrm{~mm}$, respectively.

Based on this behavior, the crystallinity was measured by DSC (see Section 2.). The results are shown as heat of crystallization $(\Delta H)$ within the chart. Thereby, $\Delta H$ is increased from $52 \mathrm{~J} \cdot \mathrm{g}^{-1}$ to $70 \mathrm{~J} \cdot \mathrm{g}^{-1}$ after one day and to $76 \mathrm{~J} \cdot \mathrm{g}^{-1}$ after seven days of aging which leads to the conclusion 

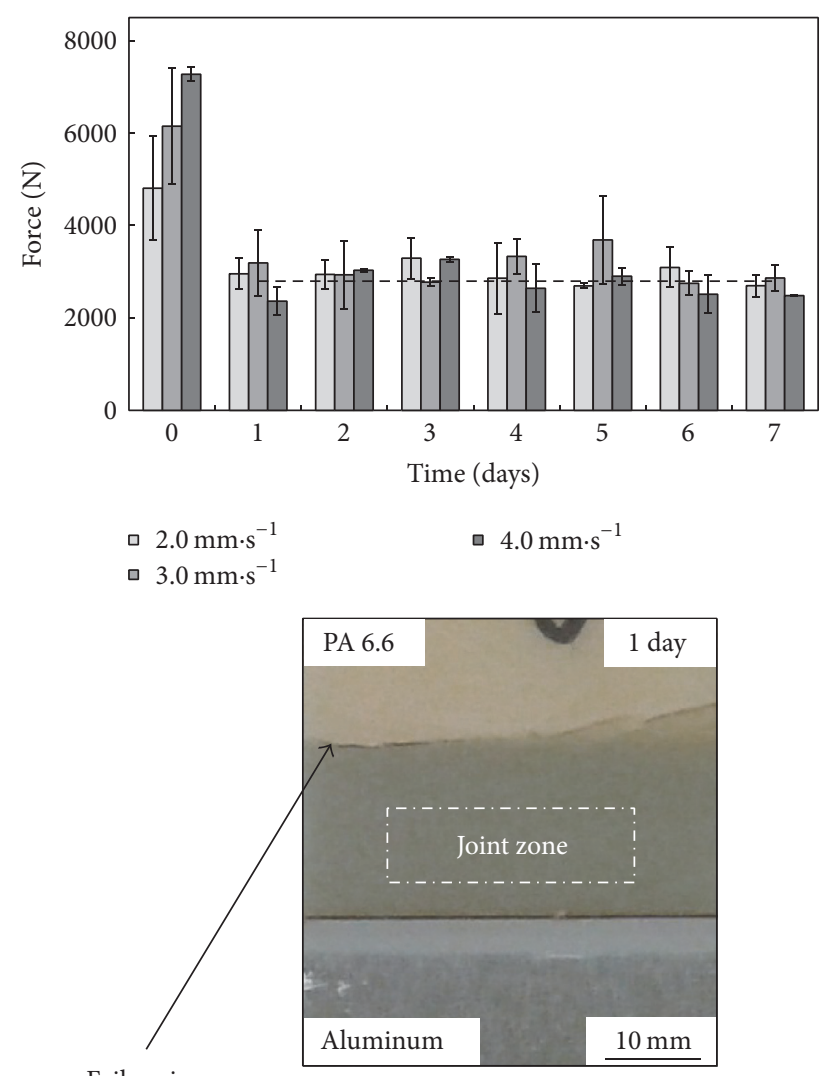

Failure in base material

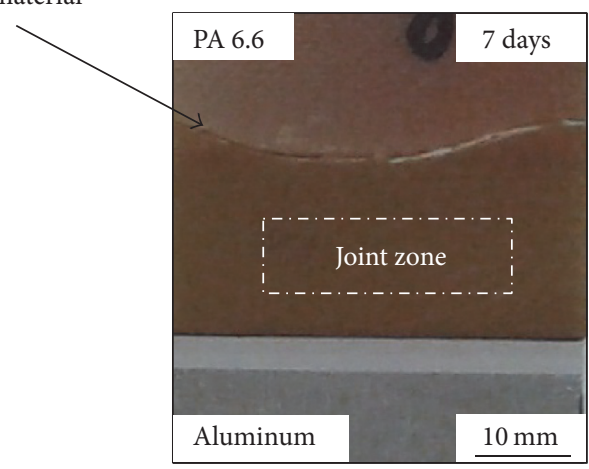

FIGURE 12: Maximum forces obtained in tensile shear testing after aging above glass transition temperature $\left(155^{\circ} \mathrm{C} \pm 3 \mathrm{~K}\right)$ and representative fracture modes.

of an asymptotic curve concerning a maximum of $\Delta H$. Increasing the degree of crystallization (as concluded by an increase in the enthalpy, $\Delta H$ ) influences elongation and also crosshead travel due to the reduced movability of the crystalline areas compared to the amorphous ones. Such increase in crystallinity and decrease in ductility led to the lower crosshead travel as shown in Figure 13. Besides an increase in crystallinity, the melting temperature was slightly reduced from $266^{\circ} \mathrm{C}$ to $263^{\circ} \mathrm{C}$ which may be an indication of chemical degradation of PA6.6.

Similar to unaged specimens, the fracture mode also occurred in plastic base material after aging above the glass transition temperature as seen in Figure 12. The mechanical

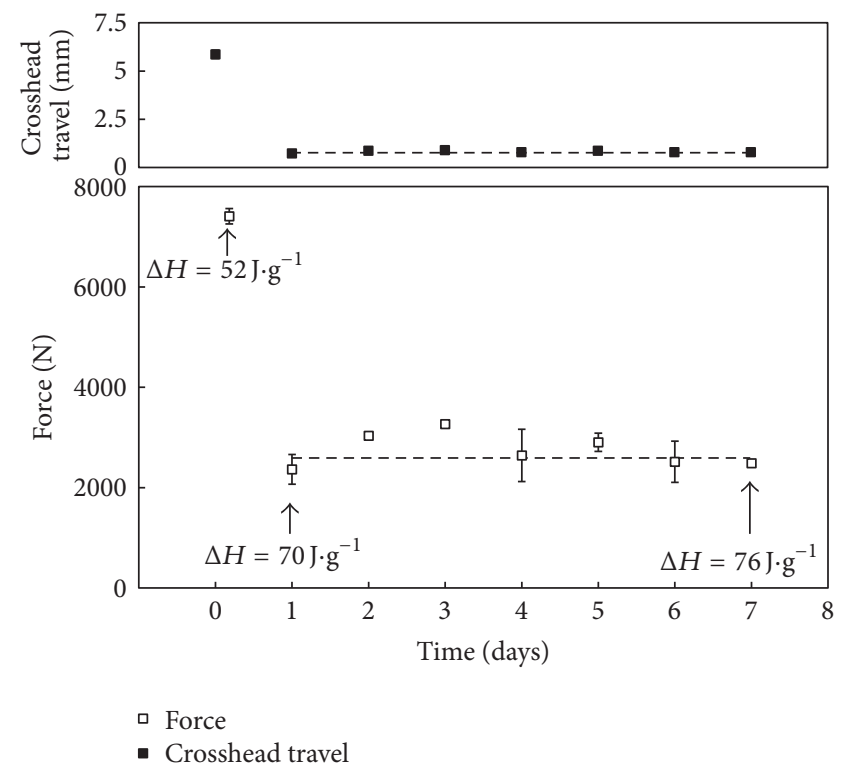

FIGURE 13: Correlation of force and crosshead travel to aging time (joining speed of $4 \mathrm{~mm} \cdot \mathrm{s}^{-1}$ ).

properties between different joining speeds in reference samples changed due to the increased degree of crystallization to a similar behavior. The brittle fracture occurred for all specimens in the investigated interval of joining speeds from 2 to $4 \mathrm{~mm} \cdot \mathrm{s}^{-1}$ and after aging the joints above the glass transition temperature of PA6.6.

\section{Conclusions}

Within this paper, the correlation between time-temperature profile, joining speed, and melting layer thickness was discussed and linked to thermoplastic morphology for lasermanufactured aluminum-polyamide 6.6 joints. Depending on different joining speeds, the mechanical behavior was characterized and three joining speeds were selected for outdoor weathering and thermal aging above the glass transition temperature at $155^{\circ} \mathrm{C} \pm 3 \mathrm{~K}$.

The fracture after tensile shear testing occurred in the plastic base material despite outdoor weathering and thermal aging for the time period considered. Also the forcecrosshead travel graphs showed a harmonized behavior due to moisture effects and increased crystallinity.

Further investigations on longer time periods, additional ambient conditions, and alternative materials, for example, polyolefins, are necessary. This allows the relation of the shown effects on morphology and mechanical properties to the impact of varied ambient conditions and material characteristics.

\section{Competing Interests}

The authors declare that they have no competing interests. 


\section{Acknowledgments}

The authors would like to thank the Department of Economy, Employment and Technology (TMWAT) in Thuringia (Germany) and the European Social Fund (ESF) for the support of the project Thermal Joining of Hybrid Structures within the research group "Polymer Based Lightweight Composite Materials in Automotive Engineering" (funding code: 2011FGR0109). They acknowledge support for the Article Processing Charge by the German Research Foundation and the Open Access Publication Fund of the Technische Universität Ilmenau. Furthermore, the authors would like to thank Dr. Seyed M. Goushegir for the fruitful discussions and his assistance in editing the manuscript.

\section{References}

[1] M. Sickert and E. Haberstroh, "Thermal direct joining for hybrid plastic metal structures," in Proceedings of the Euro Hybrid Materials and Structures, pp. 42-45, 2014.

[2] A. Roesner, S. Scheik, A. Olowinsky, A. Gillner, U. Reisgen, and M. Schleser, "Laser assisted joining of plastic metal hybrids," Physics Procedia, vol. 12, pp. 370-377, 2011.

[3] S. M. Goushegir, J. F. dos Santos, and S. T. Amancio-Filho, "Friction Spot Joining of aluminum AA2024/carbon-fiber reinforced poly(phenylene sulfide) composite single lap joints: microstructure and mechanical performance," Materials and Design, vol. 54, pp. 196-206, 2014.

[4] F. Balle and D. Eifler, "Monotonic and cyclic deformation behavior of ultrasonically welded hybrid joints between light metals and Carbon Fiber Reinforced Polymers (CFRP)," in Fatigue Behaviour of Fiber Reinforced Polymers: Experiments and Simulations, pp. 111-122, DEStech Publications, 2012.

[5] C. Ageorges and L. Ye, "Resistance welding of metal/thermoplastic composite joints," Journal of Thermoplastic Composite Materials, vol. 14, no. 6, pp. 449-475, 2001.

[6] S. Katayama, Y. Kawahito, and M. Mizutani, "Latest progress in performance and understanding of laser welding," Physics Procedia, vol. 39, pp. 8-16, 2012.

[7] K.-W. Jung, Y. Kawahito, M. Takahashi, and S. Katayama, "Laser direct joining of carbon fiber reinforced plastic to aluminum alloy," Journal of Laser Applications, vol. 25, no. 3, Article ID 032003, pp. 1-6, 2013.

[8] S. Katayama, Y. Kawahito, Y. Niwa, and S. Kubota, "Laserassisted metal and plastic joining," in Proceedings of the LANE 2007: Laser Assisted Net Shape Engineering, vol. 5, pp. 41-51, Erlangen, Germany, September 2007.

[9] Y. Kawahito and S. Katayama, "Characteristics of LAMP joining structures for several materials," in Proceedings of the 29th International Congress on Applications of Lasers and Electro-Optics (ICALEO '10), pp. 1469-1473, Atlanta, Ga, USA, September 2010.

[10] S. Arai, Y. Kawahito, and S. Katayama, "Effect of surface modification on laser direct joining of cyclic olefin polymer and stainless steel," Materials and Design, vol. 59, pp. 448-453, 2014.

[11] T. Markovits, A. Bauernhuber, and M. Géczy, "Investigating the shape locking phenomenon in case of LAMP joining technology," Physics Procedia, vol. 39, pp. 100-107, 2012.

[12] P. Amend, C. Mohr, and S. Roth, "Experimental investigations of thermal joining of polyamide aluminum hybrids using a combination of mono- and polychromatic radiation," Physics Procedia, vol. 56, pp. 824-834, 2014.

[13] A. Heckert and M. F. Zaeh, "Laser surface pre-treatment of aluminium for hybrid joints with glass fibre reinforced thermoplastics," Physics Procedia, vol. 56, pp. 1171-1181, 2014.

[14] M. Hino, Y. Mitooka, K. Murakami, K. Urakami, H. Nagase, and T. Kanadani, "Effect of aluminum surface state on laser joining between 1050 aluminum sheet and polypropylene resin sheet using insert materials," Materials Transactions, vol. 52, no. 5, pp. 1041-1047, 2011.

[15] J. P. Bergmann and M. Stambke, "Potential of laser-manufactured polymer-metal hybrid joints," Physics Procedia, vol. 39, pp. 84-91, 2012.

[16] A. Cenigaonaindia, F. Liébana, A. Lamikiz, and Z. Echegoyen, "Novel strategies for laser joining of polyamide and AISI 304," Physics Procedia, vol. 39, pp. 92-99, 2012.

[17] M. Wahba, Y. Kawahito, and S. Katayama, "Laser direct joining of AZ91D thixomolded Mg alloy and amorphous polyethylene terephthalate," Journal of Materials Processing Technology, vol. 211, no. 6, pp. 1166-1174, 2011.

[18] E. Ghorbel, G. Casalino, and S. Abed, "Laser diode transmission welding of polypropylene: geometrical and microstructure characterisation of weld," Materials and Design, vol. 30, no. 7, pp. 2745-2751, 2009.

[19] M. H. Al-Wohoush and M. R. Kamal, "Characterization of thermoplastic laser-welded joints," International Polymer Processing, vol. 27, no. 5, pp. 574-583, 2012.

[20] K. Schricker, M. Stambke, and J. P. Bergmann, "Experimental investigations and modeling of the melting layer in polymermetal hybrid structures," Welding in the World, vol. 59, no. 3, pp. 407-412, 2015.

[21] P. Amend, S. Pfindel, and M. Schmidt, "Thermal joining of thermoplastic metal hybrids by means of mono- and polychromatic radiation," Physics Procedia, vol. 41, pp. 98-105, 2013.

[22] A. Roesner, "Long term stability of laser joined plastic metal parts," Physics Procedia, vol. 41, pp. 169-171, 2013.

[23] DIN, Aluminium and Aluminium Alloys-Chemical Composition and form of Wrought Products-Part 3: Chemical Composition and Form of Products, German Version EN 573-3:2013, Beuth, Berlin, Germany, 2013.

[24] DIN, Plastics-Methods of Exposure to Solar Radiation-Part 3: Intensified Weathering Using Concentrated Solar Radiation (ISO 877-3:2009), German Version EN ISO 877-3:2010, Beuth, Berlin, Germany, 2011.

[25] K. Schricker, M. Stambke, and J. P. Bergmann, "Adjustment and impact of the thermoplastic microstructure of the melting layer in laser-based joining of polymers to metals," in Proceedings of the Lasers in Manufacturing Conference, 2015.

[26] H. Hügel and T. Graf, Laser in der Fertigung. Grundlagen der Strahlquellen, Systeme, Fertigungsverfahren, Springer Vieweg, 3rd edition, 2014.

[27] G. W. Ehrenstein and S. Pongratz, Beständigkeit von Kunststoffen, vol. 1, Hanser Verlag, 2007. 

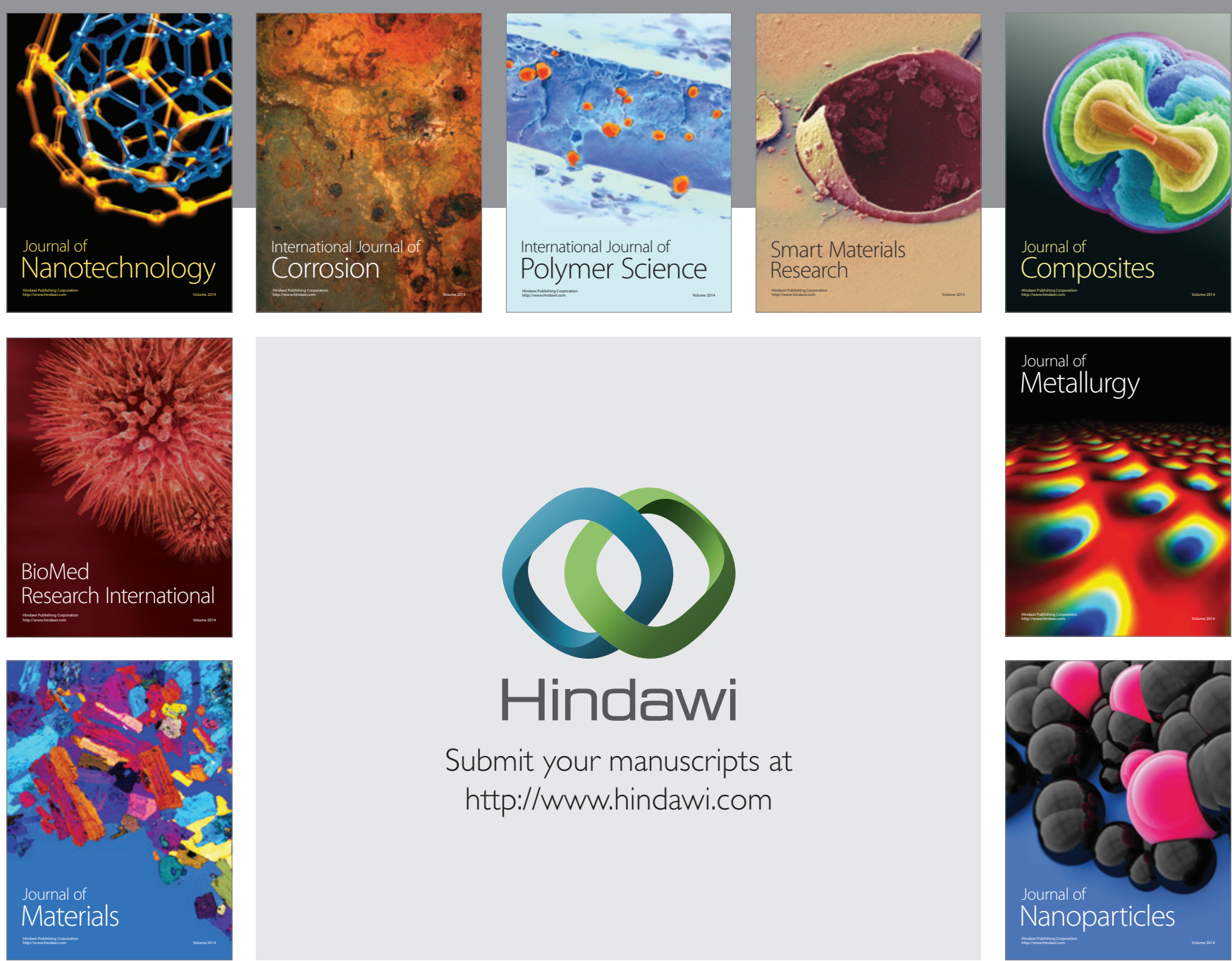

\section{Hindawi}

Submit your manuscripts at

http://www.hindawi.com

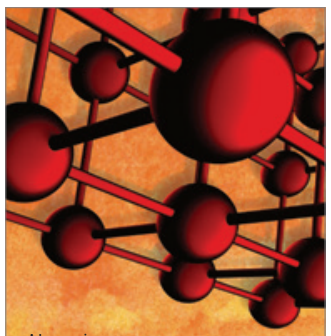

Materials Science and Engineering
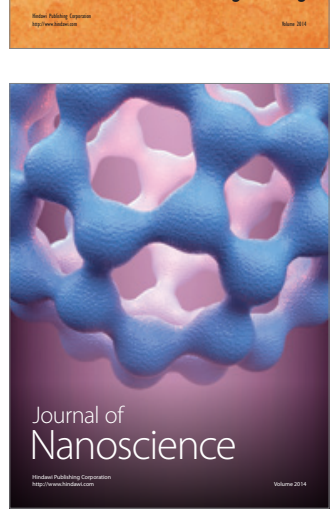
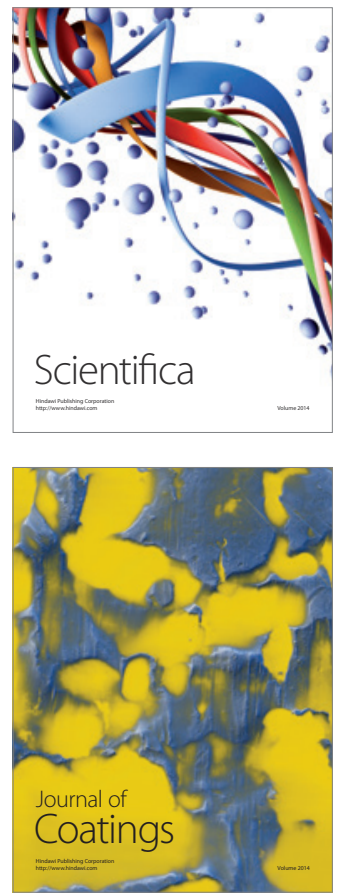
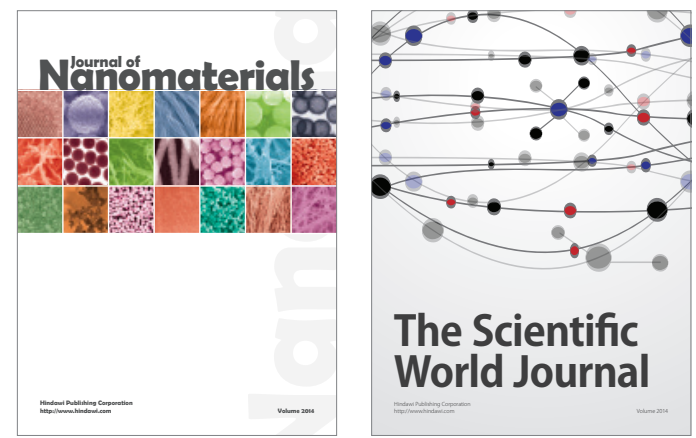

The Scientific World Journal
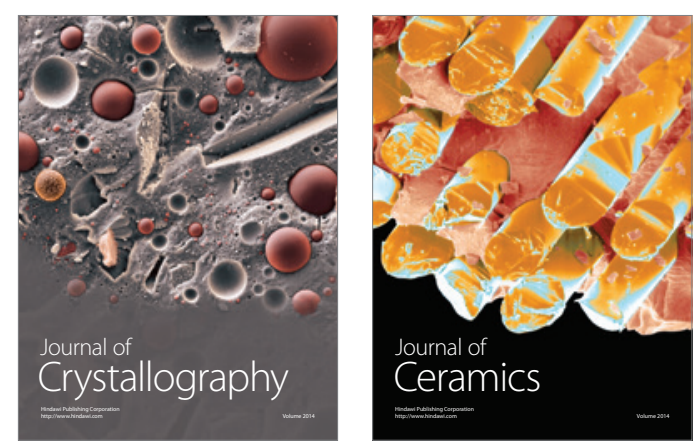
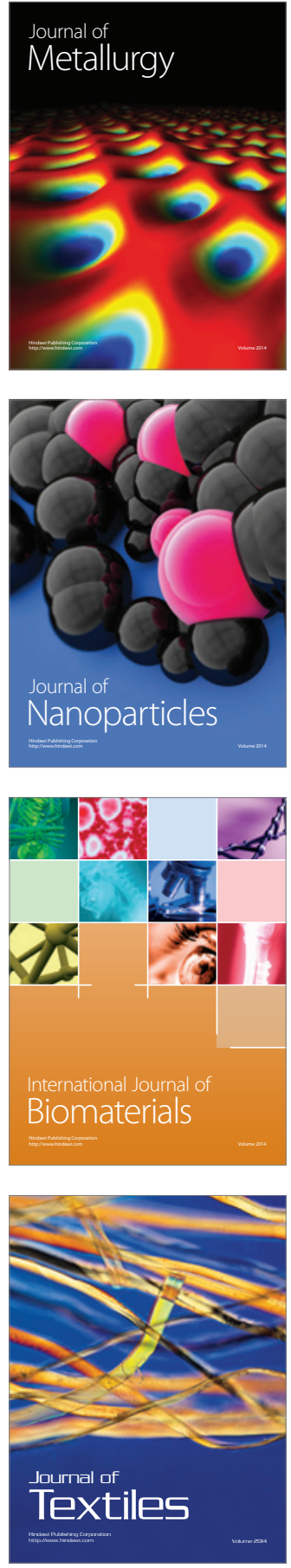